\title{
Review Article \\ Recent Developments in Reconfigurable and Multiband Antenna Technology
}

\author{
N. Haider, D. Caratelli, and A. G. Yarovoy \\ Microwave Sensing, Signals and Systems, Delft University of Technology, Mekelweg 4, 2628 CD, Delft, The Netherlands \\ Correspondence should be addressed to N. Haider; s.n.haider@tudelft.nl
}

Received 7 December 2012; Accepted 30 January 2013

Academic Editor: Renato Cicchetti

Copyright (c) 2013 N. Haider et al. This is an open access article distributed under the Creative Commons Attribution License, which permits unrestricted use, distribution, and reproduction in any medium, provided the original work is properly cited.

\begin{abstract}
A comparative analysis of various reconfigurable and multiband antenna concepts is presented. In order to satisfy the requirements for the advanced systems used in modern wireless and radar applications, different multiband and reconfigurable antennas have been proposed and investigated in the past years. In this paper, these design concepts have been classified into three basic approaches: tunable/switchable antenna integration with radio-frequency switching devices, wideband or multiband antenna integration with tunable filters, and array architectures with the same aperture utilized for different operational modes. Examples of each design approach are discussed along with their inherent benefits and challenges.
\end{abstract}

\section{Introduction}

Traditionally wireless systems are designed for single predefined mission. Therefore, the antennas of these systems also possess some fixed parameters such as frequency band, radiation pattern, polarization, and gain. Recently reconfigurable antennas (RAs) have gain tremendous research interest for many different applications, for example, cellular radio system, radar system, satellite communication, airplane, and unmanned airborne vehicle (UAV) radar, smart weapon protection. In mobile and satellite communications, reconfigurable antennas are useful to support a large number of standards (e.g., UMTS, Bluetooth, WiFi, WiMAX, DSRC) to mitigate strong interference signal and to cope with the changing environmental condition. On the other hand, in radar applications, reconfigurability at antenna level is often needed for multifunctional operation. This feature is achieved by utilizing antenna array systems that can be quickly adapted according to the mission. Therefore, a control over operating frequency, beam pointing direction, polarization, antenna gain, and so forth is required. A single RA can replace a number of single-function antennas. Thereby overall size, cost, and complexity of a system can be reduced while improving performance such as radar cross-section (RCS). This paper gives a comparative analysis of various concepts that has been utilized to design reconfigurable antennas.

\section{Design Concepts for Reconfigurable Antennas}

In recent time, many interesting and novel concepts have been developed to achieve adaptable antenna properties. Key aspects of some outstanding concepts will be addressed in the following sections. In our discussion, we mainly focus on antenna design with frequency agility. Some examples of antenna structures with polarization, bandwidth, and pattern reconfigurable property will be addressed as well.

There are basically three design approaches for achieving antenna frequency agility which are as follows:

(a) antennas integrated with electronic switches, mechanical actuators, tunable materials for reconfigurability in terms of circuital characteristics and/or radiation properties;

(b) ultrawideband (UWB) or multiband antennas integrated with tunable filters;

(c) reconfigurable/multiband arrays where the same aperture is utilized for different operational modes. 
TABLE 1: Comparison of tunable components.

\begin{tabular}{|c|c|c|}
\hline $\begin{array}{l}\text { Tunable } \\
\text { component }\end{array}$ & Advantages & Disadvantages \\
\hline MEMS & $\begin{array}{l}\text { Reduced insertion loss, good isolation, extremely high } \\
\text { linearity, low power losses, consumes little or almost no } \\
\text { DC power, wide bandwidth }\end{array}$ & $\begin{array}{l}\text { Need high-control voltage }(50-100 \mathrm{~V}) \text {, poor reliability due } \\
\text { to mechanical movement within the switch }(0.2-100 \mu \mathrm{s}) \text {, } \\
\text { slow switching speed, discrete tuning, limited lifecycle }\end{array}$ \\
\hline PIN Diode & $\begin{array}{l}\text { Needs very low driving voltage, high tuning speed } \\
(1-100 \text { ns), high power handling capability, very reliable } \\
\text { since there are no moving part, extremely low cost }\end{array}$ & $\begin{array}{l}\text { Needs high DC bias current in their on state which } \\
\text { consumes a significant amount of DC power, nonlinear } \\
\text { behavior, poor quality factor, discrete tuning }\end{array}$ \\
\hline Varactor & $\begin{array}{l}\text { The current flow through the varactor is small compared } \\
\text { to PIN diode or MEMS, continuous tuning }\end{array}$ & $\begin{array}{l}\text { Varactors are nonlinear and have low dynamic range, and } \\
\text { complex bias circuitry are required }\end{array}$ \\
\hline
\end{tabular}

\section{Tunable/Switchable Antenna Technology}

Frequency reconfiguration has become important for many modern communication systems. Therefore, there has been a notable advancement in adaptable antenna technology. Among them utilizing the same antenna aperture for different frequencies will provide the most compact solution. Relatively narrowband antennas with tunable or switchable properties are the best solution when the size and efficiency are important issues. This approach reduces the requirements of the front-end filter compared to a UWB or multiband antenna.

Frequency reconfigurable antennas are often realized by employing radio frequency (RF) microelectromechanical systems (MEMS), varactors, or PIN diodes. A comparison of these components is provided in Table 1. The MEMS components have some advantages over PIN or varactor diodes, such as reduced insertion loss, low noise figure, high quality factor, extremely high linearity, low power losses, and negligible direct-current (DC) power consumption. Recent advancements in MEMS technology enable the realization of MEMS with high switching speed and compact size. In [1], a switching time of $225 \mathrm{~ns}$ has been reported, and in [2] MEMS with dimensions as small as few $\mu \mathrm{m}$ have been shown. However, integrating a large number of lumped components (e.g., MEMS, varactor) in the radiating element might increase the power loss, noise, and complexity of the biasing circuitry. Furthermore, the power handling capability and the lifetime of these components are also important issues to take into account during the design stage.

In the following sections, some examples of reconfigurable antennas, operating mostly at the lower portion of the microwave spectrum, have been discussed. In this paper, the references are selected based on the applied technologies and design concepts.

3.1. Frequency Tuning with MEMS Switches. Reconfigurable antenna design with RF MEMS switches has gain tremendous research interest [3-12]. A dual-band tunable rectangular slot antenna was presented in [3]. In this design, the frequency tuning was achieved by utilizing the RF MEMS variable capacitor on a stub as depicted in Figure 1. The DC voltage of the MEMS is applied between the RF signal line and the ground plane which eliminated the need for additional bias

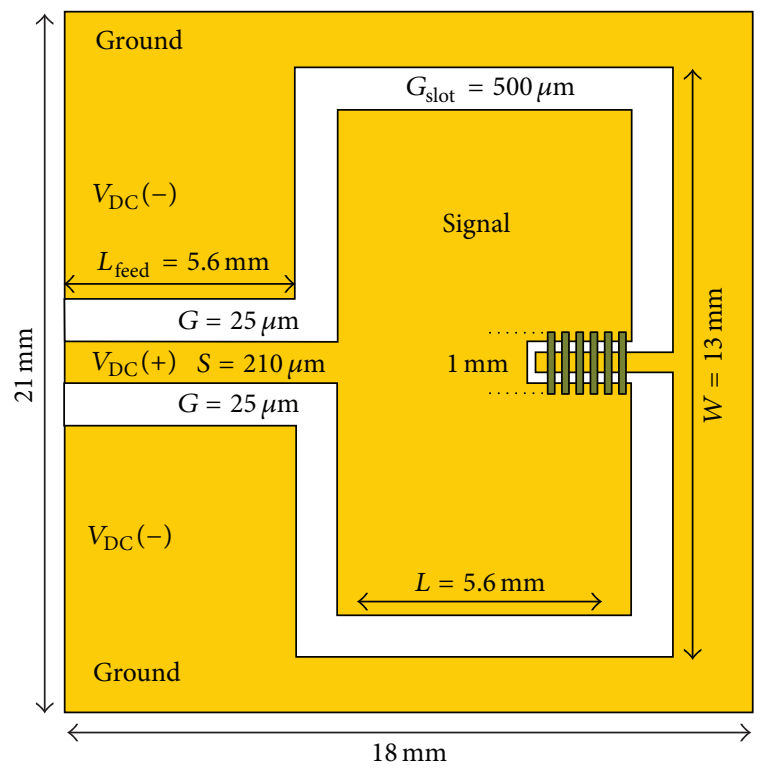

FIGURE 1: Slot-ring antenna loaded with MEMS [3].

lines. Simulation and experimental results predicted that the resonance frequencies of the antenna can be shifted from 10.22 $\mathrm{GHz}$ to $10.57 \mathrm{GHz}$ and from $7.7 \mathrm{GHz}$ to $8.7 \mathrm{GHz}$. However, in this design, independent tuning in both frequency bands is not achieved.

A capacitive MEMS loaded PIFA antenna (see Figure 2) has been studied in [4]. The outcome of this study confirmed that the antenna is capable of operating over a bandwidth of more than one octave while improving the performance in terms of specific absorption rate.

A well-known example of frequency tuning with MEMS is the pixel antenna concept (see Figure 3) which allows for switching in frequency band, polarization, and/or scan angle [5]. The disadvantage of this approach is the need of many switches which will increase the cost and the power loss, as well as the complexity of the biasing circuit.

In [7], the topology of a reconfigurable microstrip patch antenna using RF-MEMS has been presented (see Figure 4). In this study, the production cost of the antenna on quartz substrate has been reduced using only two lithographic steps. 


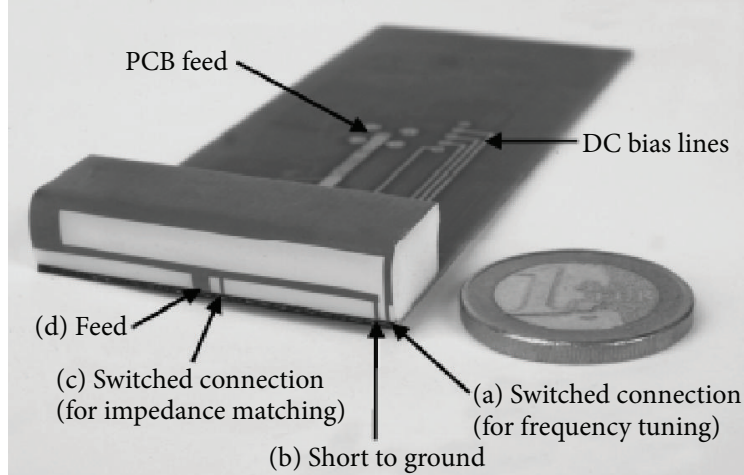

FIgURE 2: Frequency switchable PIFA antenna with MEMS [4].

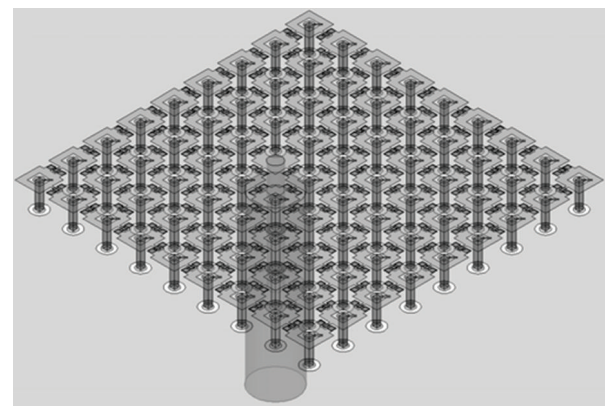

FIGURE 3: Frequency reconfigurable pixel patch antenna [6].

Therefore, this antenna has potential to be fabricated as an integrated antenna system on the chip (SoC). The results presented in [7] confirmed that the operational band of the antenna can be switched between $5.25 \mathrm{GHz}$ and $5.6 \mathrm{GHz}$. However, due to the high ohmic losses in the aluminum, this antenna structure is characterized by poor radiation efficiency.

The antenna proposed in [8] provides frequency and polarization reconfigurability. By properly selecting the ON/OFF state of different RF-MEMS (Figure 5), the antenna can be configured into right-handed circular polarization (RHCP), left-handed circular polarization (LHCP), or linear polarization. Furthermore, the resonance frequency for linear polarization shifts depending if all the MEMS are in $\mathrm{ON}$ state or OFF state. The proposed design provides impedance bandwidth of $9 \%$ relative to $10 \mathrm{~dB}$ return loss level when configured for linear polarization. For circular polarization, the fractional bandwidth is $11 \%$ although, it is to be noticed, the $-3 \mathrm{~dB}$ axial ratio bandwidth is only $1.6 \%$.

3.2. Frequency Tuning with Varactors. Integrating varactors in an antenna structure is a common way for achieving frequency agility [13-18]. In [13], a new and simple antenna topology for frequency and polarization diversity is presented (Figure 6). In this design, the resonating microstrip radiator consists of several smaller patches which are interconnected by varactors. These varactors are independently biased to change the electrical lengths of the corresponding patches

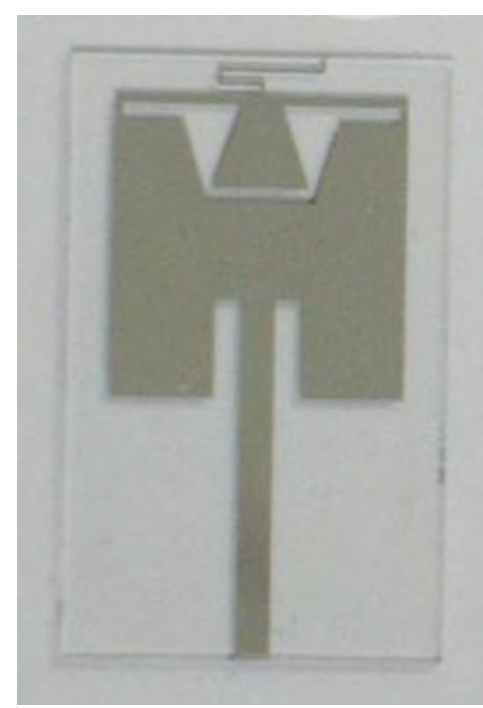

FIGURE 4: Frequency switchable antenna based on MEMS technology [7].

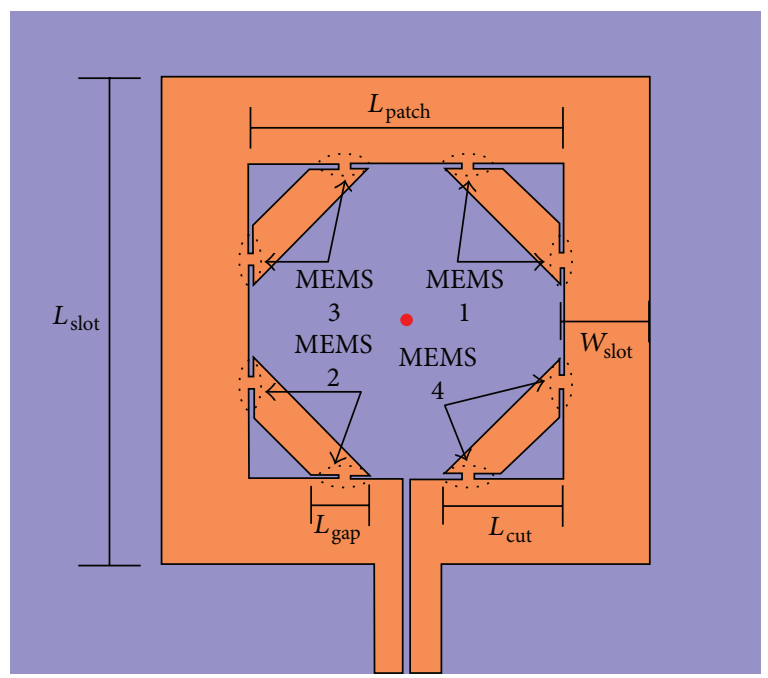

FIGURE 5: Frequency and polarization agile patch antenna [8].

and thereby change the resonant frequency of the corresponding modes. In addition, unbalanced biasing of varactor sets electrically shifts the feed point out of the antenna center. In this way, the real part of the feed-point impedance has been modified to obtain the desired optimal impedance matching. The angular position of the feed point defines the antenna polarization state. So, the whole microstrip structure can be adjusted in terms of electrical size, shape, and feed-point location, while maintaining its well-known characteristics.

A differentially fed microstrip antenna with frequency tuning capability has been presented in [14] where varactor diodes have been utilized to tune the operational band (see Figure 7). In [17], adjustable high impedance surface (HIS) using varactor diodes has been utilized in an active reflectarray (Figure 8). The reflection phase coefficient of these unit cells can be controlled by changing the capacitance 


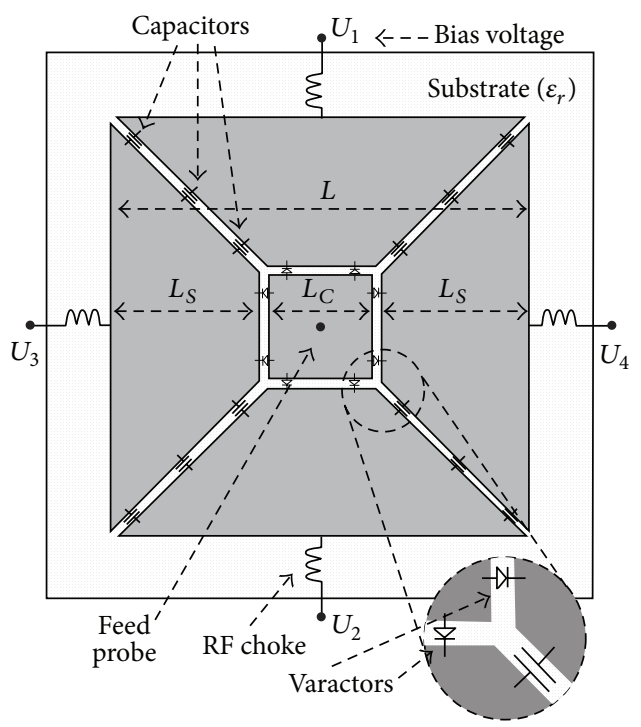

FIGURE 6: Varactor-loaded patch antenna [13].

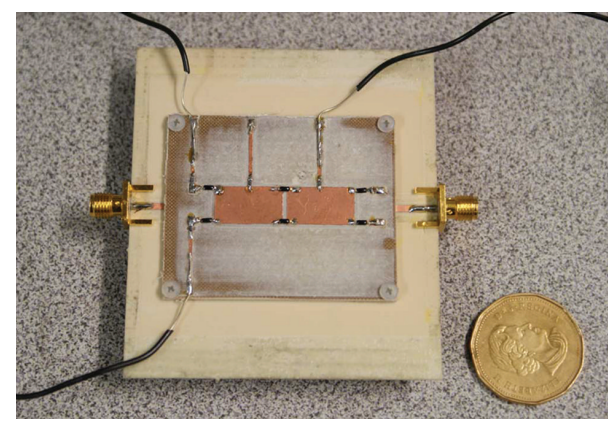

FIGURE 7: Frequency tunable differentially fed patch antenna [14].

values of these varactors. This ability to change the phase of the reflection coefficient of the unit cell gives the possibility to reconfigure the radiation pattern of the array.

3.3. Frequency Tuning with PIN Diodes. Many antenna engineers use PIN diode as the switching component [18-29]. In [18], a reconfigurable meander radiator is proposed which is composed of three PIN diodes and one varactor diode (see Figure 9). In this respect, the varactor diode is useful to adjust the resonant frequency in a fine way. It has been demonstrated that, by properly selecting the state of the diodes, the resonant frequency can be tuned from $470 \mathrm{MHz}$ to $1080 \mathrm{MHz}$.

In the study presented in [19], a switchable Vivaldi antenna has been demonstrated to provide either a narrowor wideband frequency response. As it can be noticed in Figure 10, ring slots bridged by PIN diode switches have been inserted in the radiating element to obtain a narrowband resonating behavior at different frequencies. On the other hand, the PIN diodes are deactivated wherein a wideband operation is desired.

A frequency reconfigurable $\mathrm{L} / \mathrm{S}$ band phased-array antenna has been studied in $[20,21]$. As illustrated in
Figure 11, square-ring loaded probe-fed reconfigurable patch elements were arranged in such a way that half wavelength element spacing has been maintained at both frequency bands and hence provides wide angle scanning at both bands.

In [22], a polarization reconfigurable slot antenna is proposed. Here the antenna polarization can be switched between vertical and horizontal polarization by changing the feeding structure between CPW feed and slotline feed. The geometry of the antenna is presented in Figure 12. The operating modes of the CPW-to-slotline transition are shown in Figure 13. When PIN 1 is ON and PIN 2 is OFF, the structure operates in the CPW mode. The slotline mode is activated when PIN 2 is ON and PIN 1 is OFF. In this case, the right slotline is used to feed the horizontal polarization. The electric field distribution of this design for two orthogonal polarizations is presented in Figure 14.

The proposed method provides polarization agility with single feed line. The test result of this structure indicates a wideband operation $(>25 \%)$. However, the reduced polarization purity is a limiting factor. Furthermore, the implementation of the PIN diode in the CPW line might degrade the antenna performance.

3.4. Mechanically Reconfigurable Antennas. The antenna topologies discussed above utilized lumped tunable components. More recently for applications where RF switches are not desired due to the additional power losses in the switches and complexity of the bias lines, mechanically reconfigurable antennas are being investigated [30-32]. Mechanically reconfigurable antennas are promising devices which can provide reduced RF loss, higher isolation, and better linearity with respect to antenna structures integrated with electronic switches. Nevertheless, practical issues, such as the total size and overall complexity of the system, need to be considered. In [30], a rotatable antenna has been designed for cognitive radio to tune the operational band from 2 to $10 \mathrm{GHz}$.

Mechanically reconfigurable antennas have also been used to achieve pattern diversity with a single radiating element. For systems which do not require fast pattern reconfiguration, this approach is attractive to replace the need of expensive phased array. In [31], a square ring antenna with a bendable parasitic plate has been used for machineto-machine (M2M) communications (see Figure 15).

3.5. Frequency Reconfigurability by Tunable Materials. Reconfigurability with tunable material is a very new research area and still facing challenges such as reliability, efficiency, and proper modeling. However, in recent times many researches are carried out in this region and notable achievements have been reported [33-38]. Ferroelectric dielectric materials can be used for reconfigurable antennas as their permittivity changes with the applied DC bias voltage (see Figure 16) [33]. Disadvantage of this type of material is the large bias voltage required to change the dielectric constant and high losses of the material. However, some results indicated that this type of antenna can provide higher directivity, narrow main lobe, and lower side lobes level than conventional phased array. 


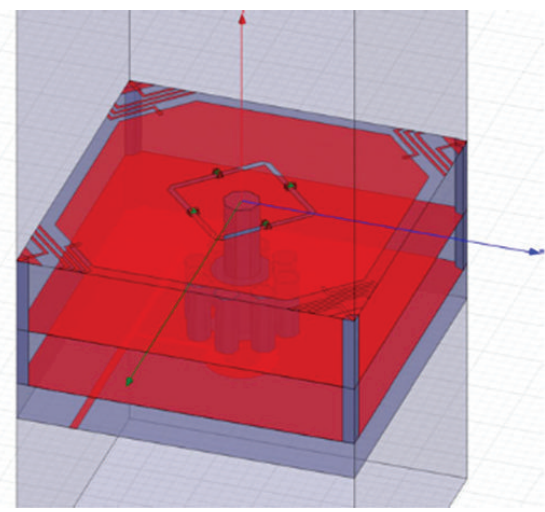

(a)

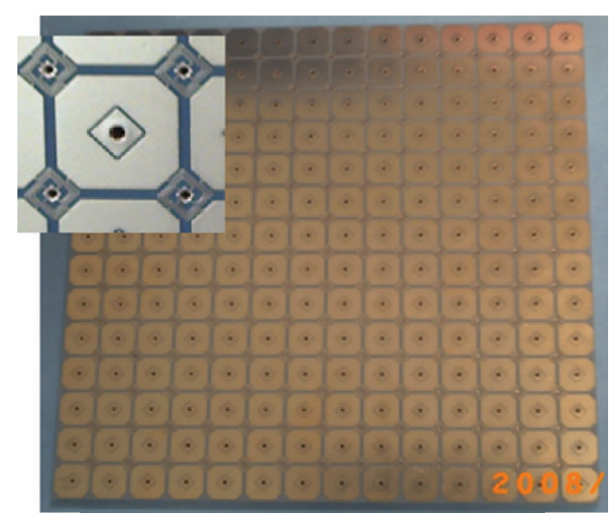

(b)

FIGURE 8: Basic geometry of the unit cell (a) and the array structure (b) of an adjustable high impedance surface [17].

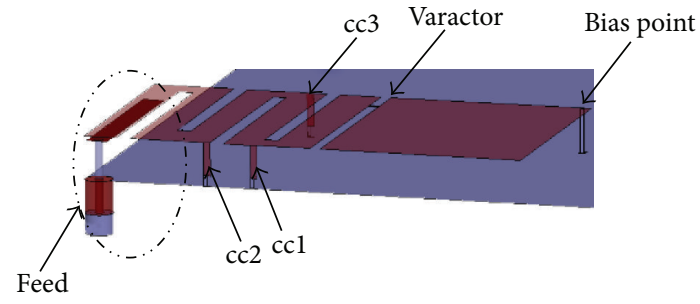

FIgURE 9: Reconfigurable meander antenna loaded with PIN diodes $(\mathrm{ccl}, \mathrm{cc} 2$, and $\mathrm{cc} 3)[18]$.

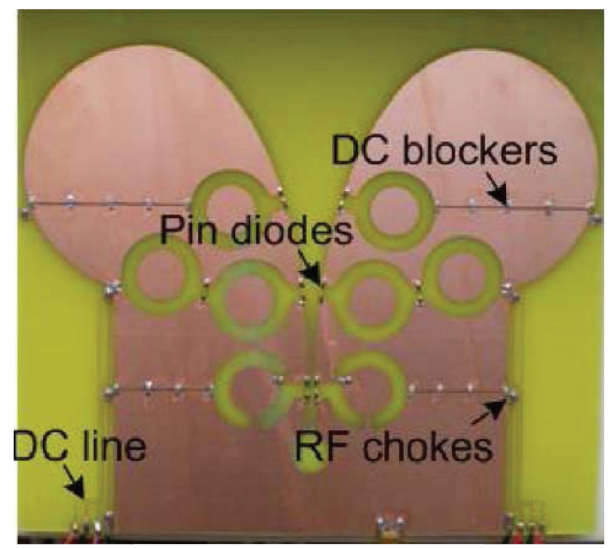

FIGURE 10: Switchable Vivaldi antenna [19].

In [34], a waveguide slot antenna with reconfigurable aperture is presented (see Figure 17). The reconfigurable aperture consists of a number of surface PIN diodes (SPIN). The conductivity of SPIN changes proportionally to the plasma density. These SPIN diodes can be activated or deactivated to produce the desired radiation pattern. Therefore, additional flexibility can be achieved compared to conventional waveguide slot antennas. In this design, plasma regions which have relatively high electrical conductivity can be temporarily created inside a silicon substrate. This way a different antenna configuration can be created. For this, a semiconductor chip

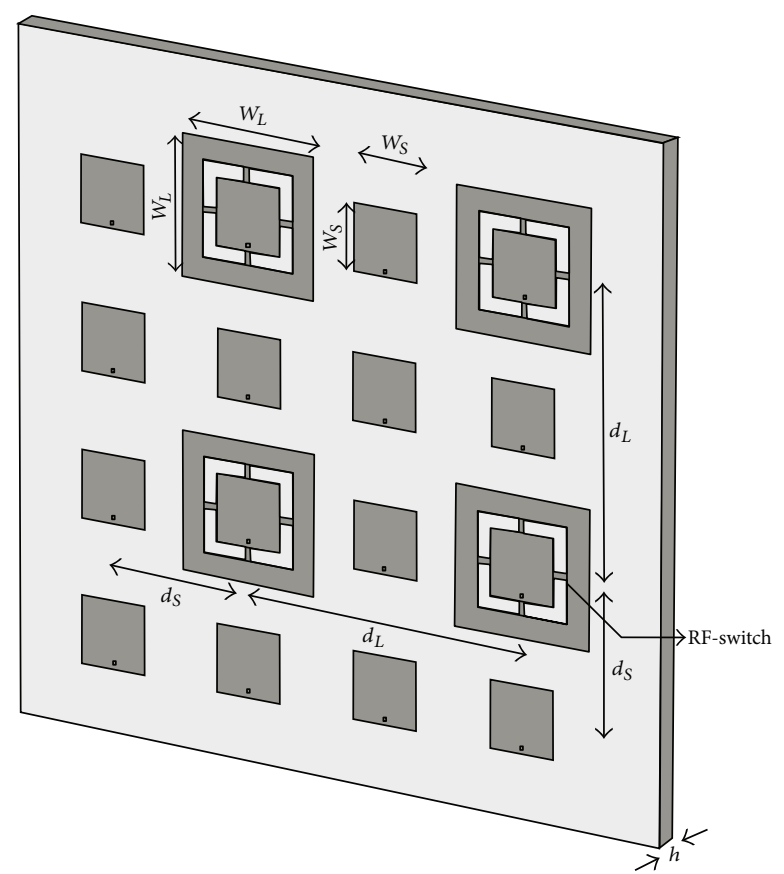

FIGURE 11: Reconfigurable ring-loaded patch antenna array [20].

has been used which contains the PIN structures. The chip acts as a planar dielectric waveguide and electromagnetic waves can propagate in it. It has been claimed in [34] that the plasma of carriers created by forward biased PIN structures locally affects the wave propagation velocity and helps to steer the beam within a wide steering angle.

Another example of reconfigure antenna with tunable material property is the plasma antenna. Metal-like conductive plasma channels in high-resistivity silicon can be activated by the injection of a suitable DC current [35]. The proposed structure is illustrated in Figures 18 and 19. One metal on alumina and three identical plasma islands constitute the monopole antenna. The plasma channels are 


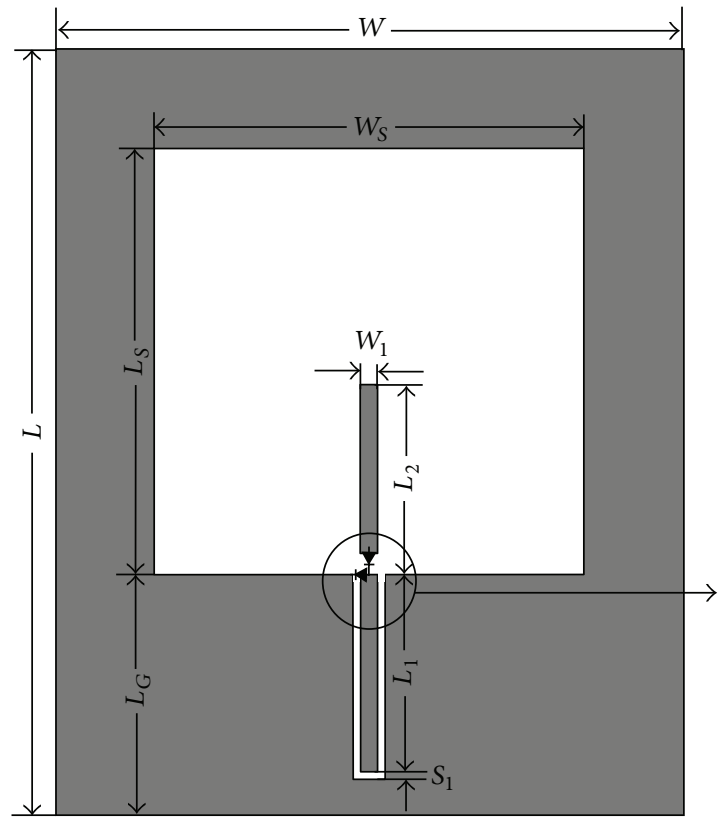

(a)

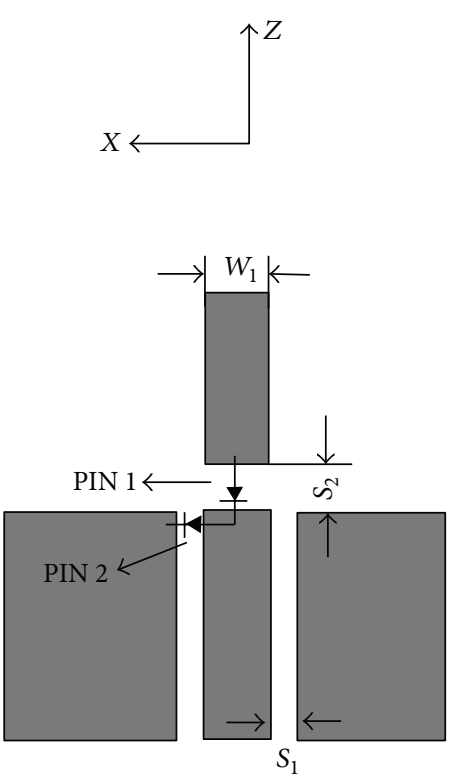

(b)

FIGURE 12: Geometry of a reconfigurable slot antenna [22].

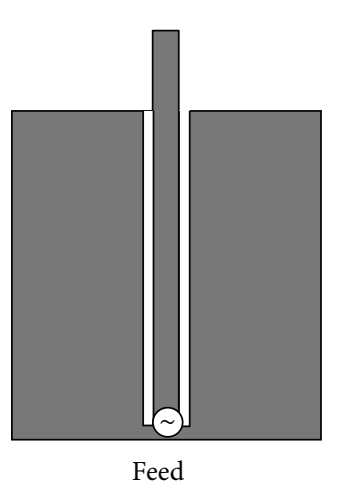

(a)

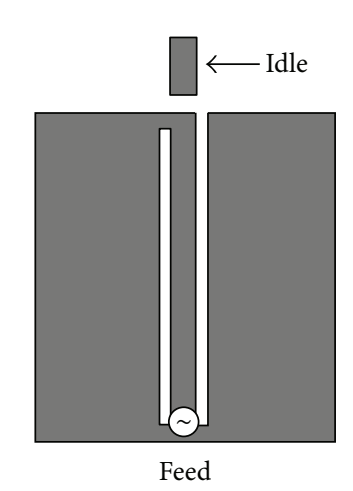

(b)
FIGURE 13: Feeding structure of the reconfigurable slot antenna: (a) CPW mode; (b) slotline mode [22].

realized by using high-resolution silicon fabrication technology. It has been pointed out in [35] that these reconfigurable antennas enable frequency hopping, beam shaping, and steering without the complexity of RF feed structures. The approach presented in [35] can provide high resolution due to the advancements in semiconductor technology.

A new approach which has recently gained a lot of research interest is the liquid crystal tunable antennas. The permittivity of a liquid crystal can be varied with DC bias voltage. Liquid crystals (LCs) are substances whose phase of matter has properties of both a conventional liquid and a solid crystal. The dielectric permittivity of an LC can be varied by orienting its molecules with an electrostatic or magnetostatic field or by surface interaction with a mechanically rubbed polyamide film. Researches of Sheffield University have demonstrated an LC tunable microstrip patch antenna at $5 \mathrm{GHz}$ [36] with a tuning range of $4-8 \%$ (see Figure 20). However, due to the high losses in the LC material, the antenna suffered from poor efficiency (20-40\%).

It is, however, to be noticed that, while the electromagnetic behavior of LCs is well understood at optical frequencies, the use of LCs at microwave and millimeter-wave frequencies requires first their electromagnetic characterization in terms of dielectric properties at these frequencies. The available literature on this topic is limited to a few LC mixtures. Overall it appears that a careful design of the mixture is of crucial importance for the applicability of this type of material in reconfigurable devices. Besides the above-mentioned reconfigurable concepts, other promising research areas are emerging, such as the exploitation of microfluidics $[39,40]$, optical controls $[41,42]$, and graphene $[43,44]$ in reconfigurable antennas.

\section{Wideband Antenna Integration with Tunable Filters}

In Section 4, some examples of reconfigurable antenna with tunable or switchable components have been provided. Another approach is to use ultrawideband or multiband antenna elements [45-60]. In this approach, one needs antenna solutions which feature good performance (good impedance matching, radiation pattern, gain, etc.) for the whole bandwidth of interest and a tunable filter will be used to select the operational frequency band. Furthermore, for phased-array application, unidirectional radiation is required. 


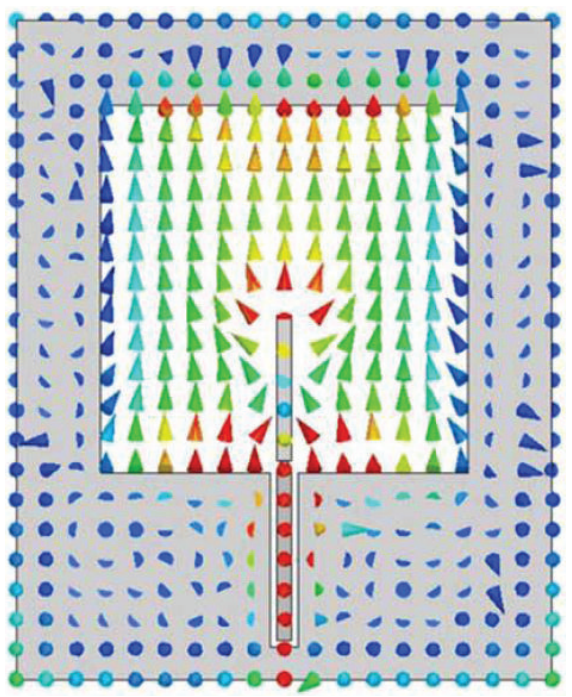

(a)

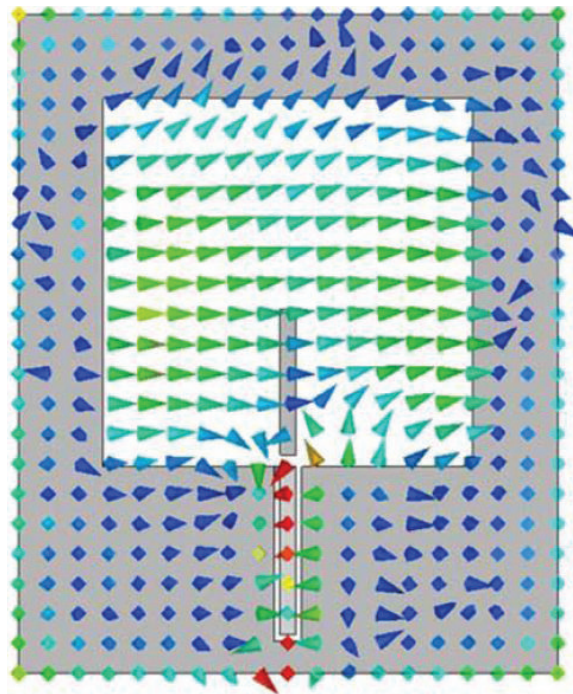

(b)
$.0000 e+003$

$9.2864 e+002$

$8.5729 e+002$

$7.8593 e+002$

$7.1457 e+002$

$6.4321 e+002$

$5.7186 e+002$

$5.0050 e+002$

$4.2914 e+002$

$3.5779 e+002$

$2.8643 e+002$

$2.1507 e+002$

$1.4371 e+002$

$7.2357 e+001$

$1.0000 e+000$

FIGURE 14: Electric field distribution within the reconfigurable slot antenna: (a) CPW mode; (b) slot-line mode [22].

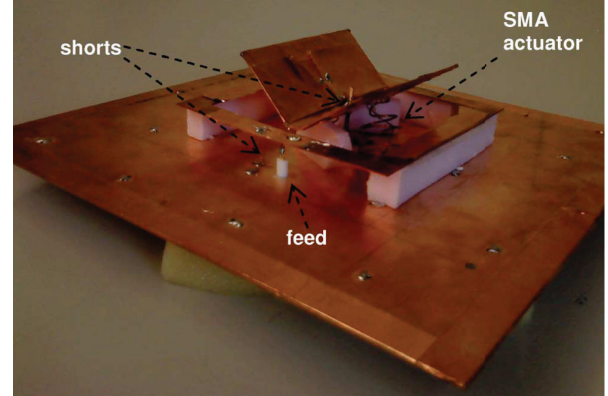

FIGURE 15: Reconfigurable square ring-patch antenna with dual-flap ground-shorted parasitic patch [31].

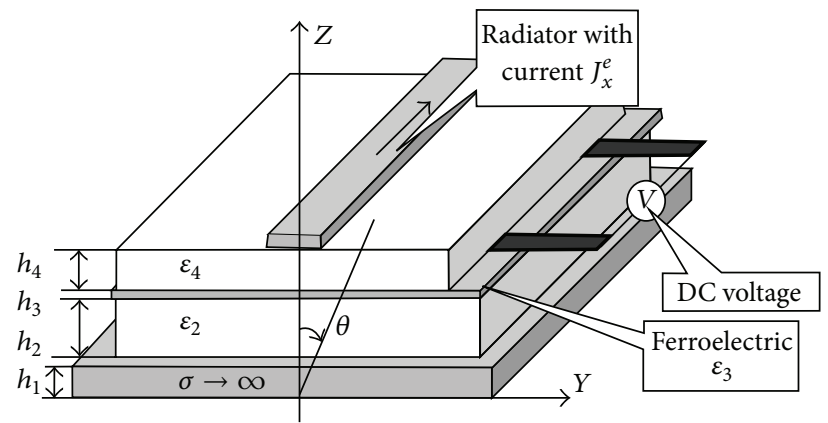

FIGURE 16: Ferroelectric antenna concept [33].

There has been a lot of broadband antenna design for different applications. For instance, transversal electromagnetic (TEM) horn or dielectric filled waveguide antenna can provide extremely wide bandwidth with directive radiation pattern. End fire wideband antennas, such as antipodal Vivaldi antennas and linear tapered slot antenna (LTSA)

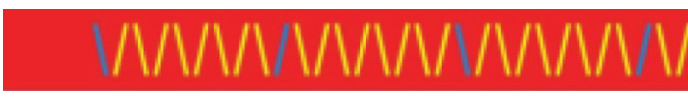

(a)

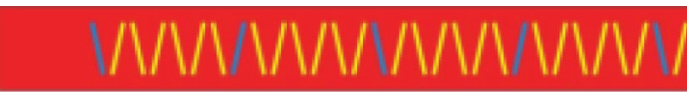

(b)

\section{I/N //I I/N/ $/ / / / / \Lambda$}

State "on"
State "off"

(c)

FIGURE 17: Slotted waveguide antenna [34].

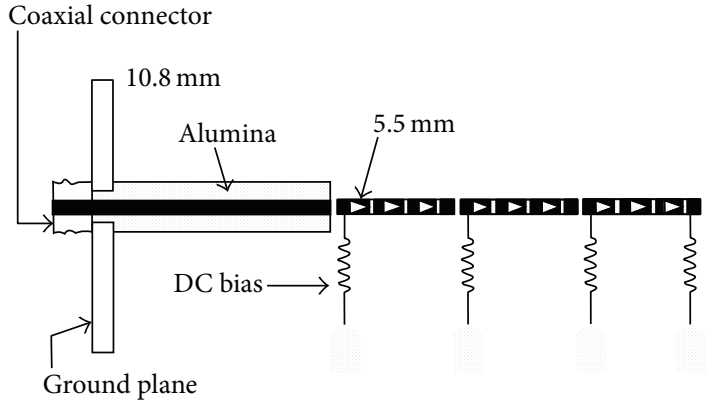

FIGURE 18: Assembled monopole unit [35].

can also be used for phased array. Dual polarized Vivaldi antenna arrays (see Figure 21), can be designed for more than 10:1 bandwidths while scanning $45^{\circ}$ or more. But to date, the high cross-polarization and high mutual coupling 


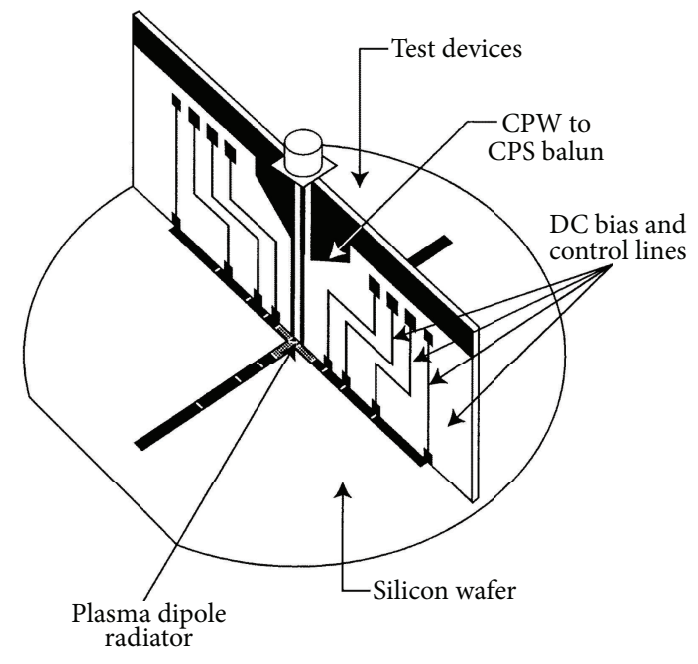

FIgURe 19: Monolithic dipole on a silicon wafer [35].

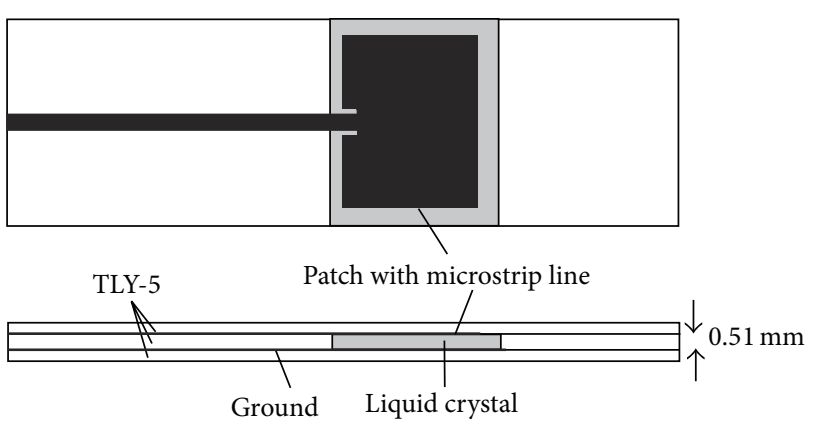

FIGURE 20: LC tunable microstrip patch antenna [36].

between the elements have been a major limiting factor. Other potential candidates of UWB phased-array element are the 3D monopole antenna (fat monopole, tab monopole, cylindrical monopole) and dielectric resonator or dielectric lens antenna. Nevertheless, there are some challenges when UWB antenna element is utilized in multifrequency radar system. Firstly, antenna performance should be good and consistent over a very wide frequency band. Furthermore, this approach requires filters with very high out-of-band noise rejection capability.

An alternative solution is to place the filter in the radiating element itself. This will relax the preselect filter requirements. An example of this design approach is provided by the reconfigurable Vivaldi antenna presented in [16], where a bandpass filter is integrated in the feeding line of the radiating structure resulting in a frequency switchable filtenna. As shown in Figure 22, a varactor diode is inserted within the filter structure in order to provide frequency reconfiguration capability. This concept is attractive since it does not require the insertion of switching component directly in the radiating element.

In [47], a directive UWB antenna with large fractional bandwidth has been designed for full-polarimetric array. As depicted in Figure 23 in this study linearly polarized antennas are grouped together and fed in such a way that

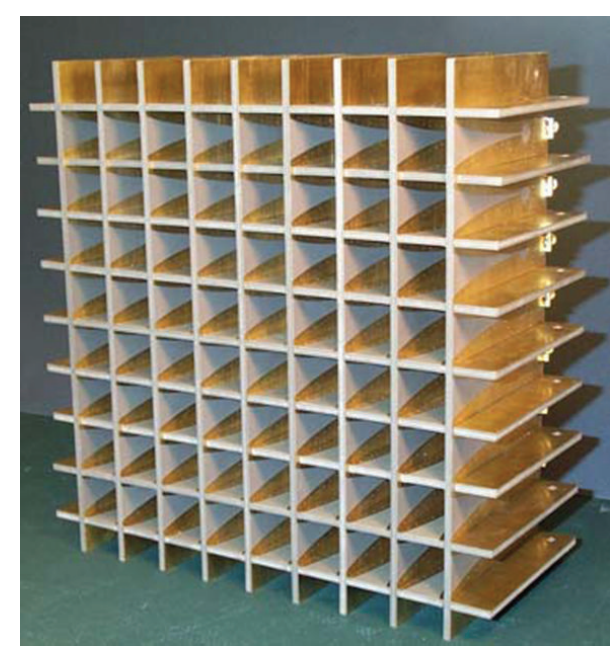

FIgURE 21: Dual-polarized Vivaldi array [45].

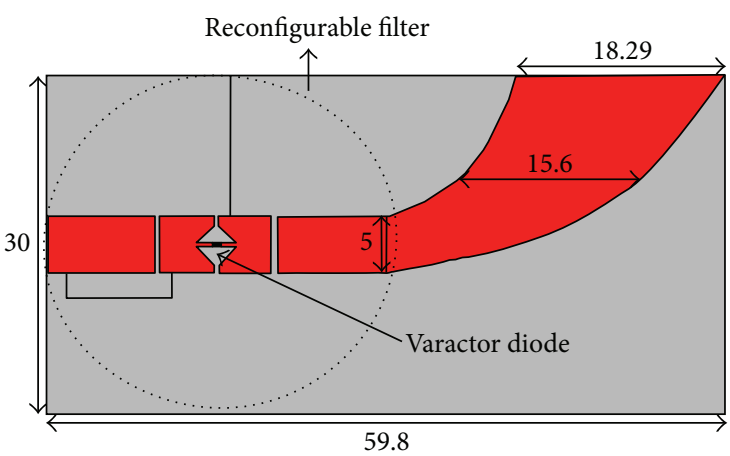

(a)

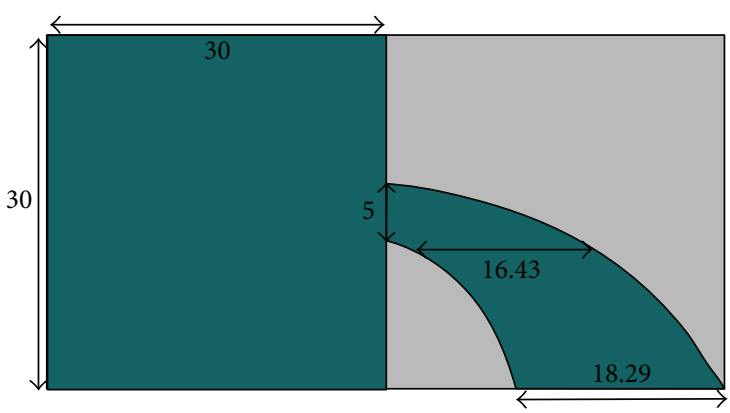

(b)

FIGURE 22: Frequency reconfigurable filtenna: (a) top layer and (b) bottom layer [16].

they can radiate fields in two orthogonal planes while maintaining their wideband properties. A nondispersive wideband antenna has been used as the radiating element. The antenna concept is based on the combination of the electromagnetic characteristics of a loop and a planar monopole $[48,49]$.

\section{Reconfigurable Array Structures}

In the two approaches detailed in the previous sections, the same radiating element is used for different frequency 


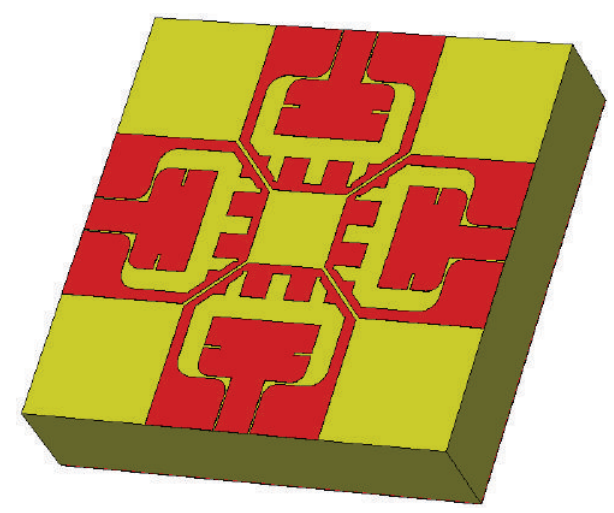

FIGURE 23: Dual-polarized UWB subarray [47].

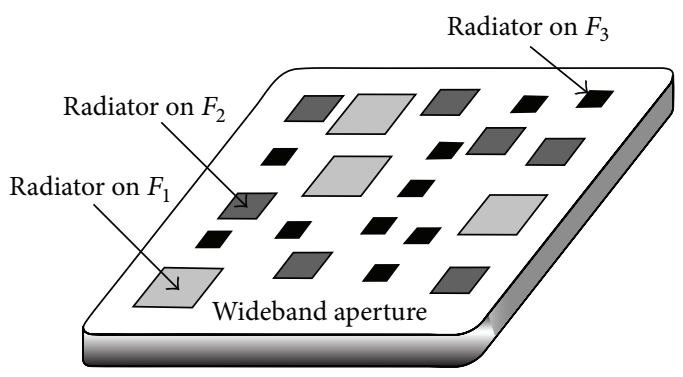

FIGURE 24: Shared aperture antenna [61].

bands. An alternative solution is to employ different radiating elements for different antenna performances. Advantages of this approach are the simple configuration and frequency jumps that can be extremely large. However, for this approach separate antenna arrays and feeding networks are required which will increase the total size.

5.1. Shared Aperture Antennas. The shared aperture antenna is one example of the mentioned design concept. In this approach, the idea is to share the physical area of the antenna aperture between different subarrays. The concept is illustrated in Figure 24. Here interleaved matrix of radiators is used [61]. This concept can be utilized for multifrequency, multifunction, and multipolarization applications. The advantage of shared aperture antenna is possibility to perform multiple tasks, achieve narrow beam width, avoid amplitude tapering, and so forth. The main challenges related to shared aperture antenna is to design subarrays which satisfies their requirements and placing the elements on the same aperture while avoiding any physical overlapping.

Another notable example of multiband array is presented in [62]. Here an interleaved phased array is utilized with waveguide element and wideband tapered element (see Figure 25). The array operates in triband and $\mathrm{C}, \mathrm{X}$ and $\mathrm{Ku}$ band. The waveguide element operates at $\mathrm{Ku}$ band and the wideband "bunny ear" element operates at $\mathrm{C}$ to $\mathrm{X}$ band. In this design, the two types of elements are orthogonally polarized and therefore isolation between them is very high. However, the coupling between two adjacent wideband

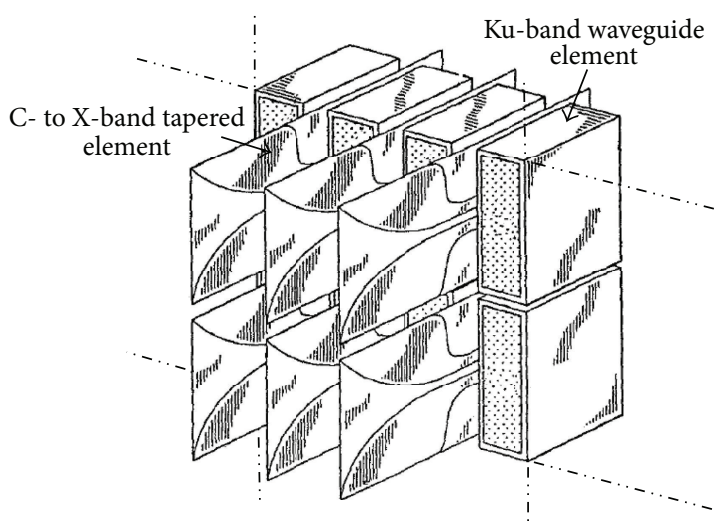

FIGURE 25: Multiband phased-array antenna with interleaved elements [62].

elements is very high, this being the major limiting factor for the array performance.

5.2. Multilayer Antennas. An alternative solution of shared aperture antenna is multilayer antenna array. In [63], a dualfrequency dual-polarized array antenna is presented (see Figure 26). Two planar arrays are incorporated for simultaneous S- and X-band operation. Rectangular ring resonator and circular patches are used as the radiating elements at $\mathrm{S}$ and $\mathrm{X}$ bands, respectively. These circular patches are combined to form the array using a series-fed structure to save the space of the feeding line network. The S-band elements are placed on the top substrate, and a foam layer is used to separate the array. One of the important design considerations for any multilayer array is that the antennas operating at different bands should be nearly transparent to each other to avoid performance degradation.

For reflector antennas frequency agility can be achieved by mounting several feed horns about the focus (with some degradation of pattern characteristics). Reflector type antenna has very high efficiency but requires mechanical movement to steer its beam. Furthermore, it is not flat and not easy to integrate on a host platform, and is significantly bulkier than planar antennas. As a result reflectarray antennas are often used. These are low cost, low profile, and high gain antennas with the beam scanning capability of a phasedarray antenna. However, the disadvantage of reflectarray is the limited bandwidth caused by the narrow bandwidth of the elements and the different phase lengths needed at each frequency for beam steering. Dual frequency reflectarray can be designed by using dual layers of radiating elements [64]. An example of dual frequency reflectarray is presented in Figure 27.

Another notable example of multiband array is presented in [65]. As the S-band elements, dipoles are used while square patches are used as the X-band element (see Figure 28). The dual frequency ratio is here $1: 3$. The measured bandwidth of VSWR $<2$ are $8.9 \%$ for S band and $17 \%$ for X band. The disadvantage of this approach is the complex fabrication process due to the five substrate layers. Furthermore, every 

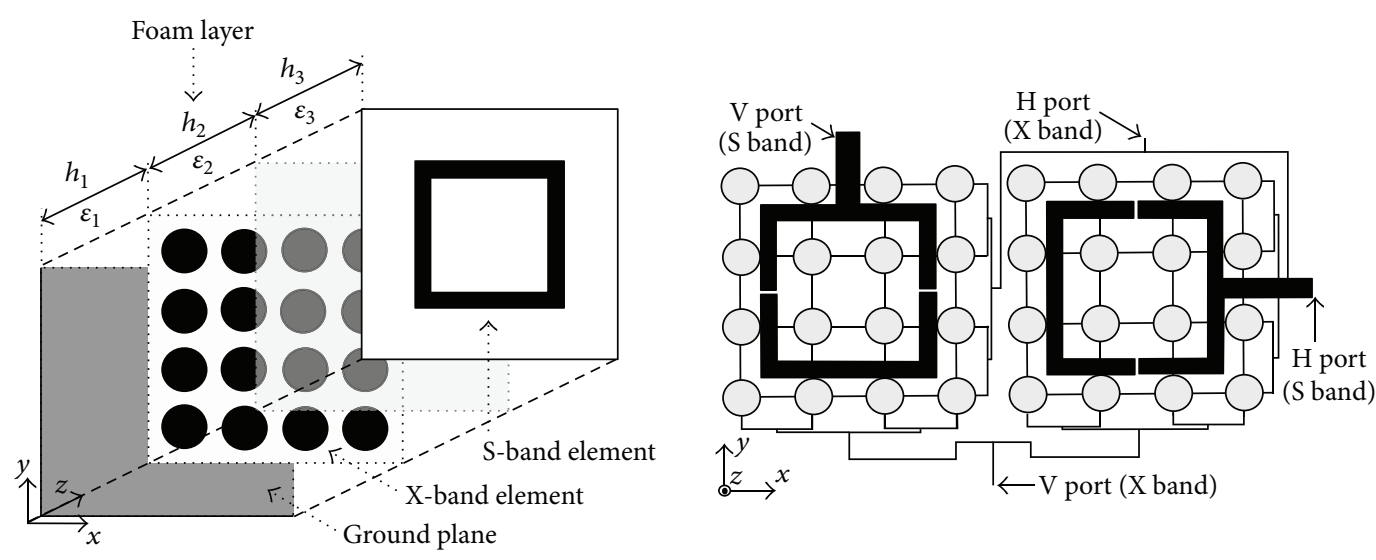

FIGURE 26: A dual-polarized planar-array antenna for S and X band [63].

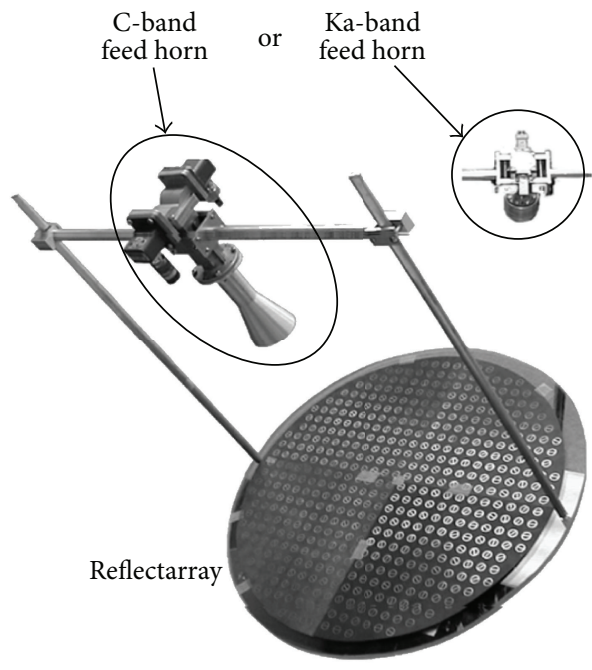

(a)

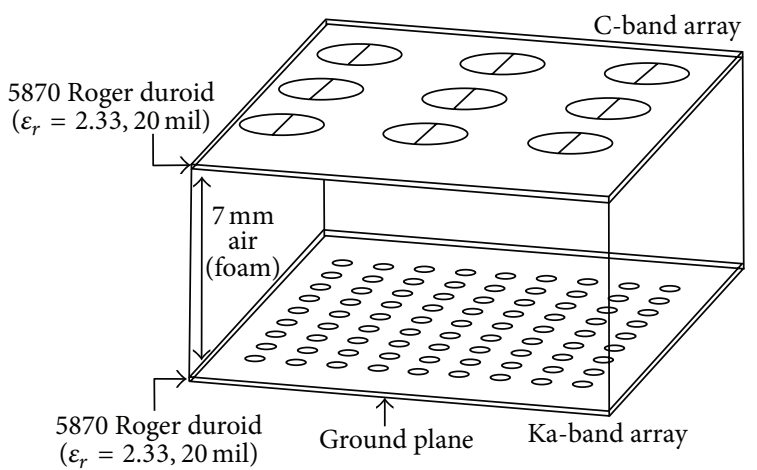

(b)

FigURE 27: Dual-layer reflectarray topology [64].

dual-polarized antenna element of both bands has two coaxial connectors beneath the substrates of the antenna. Therefore, a large number of connectors is required for the array structure. As stated in [65], a dual-polarized $2 \times 1 \mathrm{~S}$ band or $7 \times 4 \mathrm{X}$-band array will need 60 coaxial connectors.

\section{Conclusions}

Reconfigurable antennas have their applications in numerous areas such as communications and surveillance. They possess the properties to modify the relevant circuital characteristics and/or radiation properties in real time. The implementation of several functionalities on the same antenna requires topological reconfigurability to achieve radiation pattern and frequency agility. In particular, parameters such as the shape and size of the array and the grid spacing should be changed to adapt to the requirements set by the considered functionality. Moreover, digital beam forming in transmit and receive would offer great flexibility in the definition of the field of view and coverage. This requires both the possibility to choose the most suited beam-forming algorithm and corresponding calibration procedure. The antenna element can be reconfigured to obtain frequency, polarization, and/or radiation pattern agility. Frequency agility can be intended either as the ability to switch between different operating frequency bands (linked to the sensor application), for example, in a multifunctional system, or to tune the centre frequency of the instantaneous bandwidth within the total operating bandwidth of a specific communication or sensing functionality. The first case requires reconfigurability not only at antenna element level, with switching components such to obtain proper antenna operation within the aimed frequency bands, but also at array topology level, to correspondingly adapt the array spacing. The second case considers narrowband elements whose centre frequency is tuned with tunable components or substrates. Polarization agility refers to the ability to change the polarization of the transmitted/received electromagnetic field, for example, between two orthogonal 


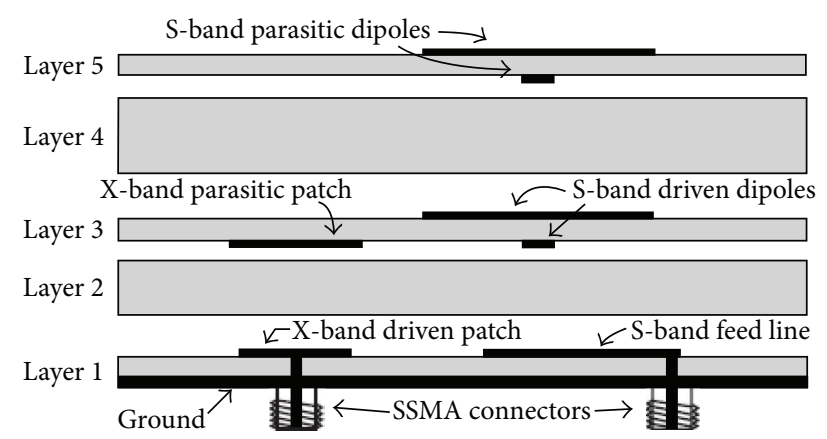

(a)

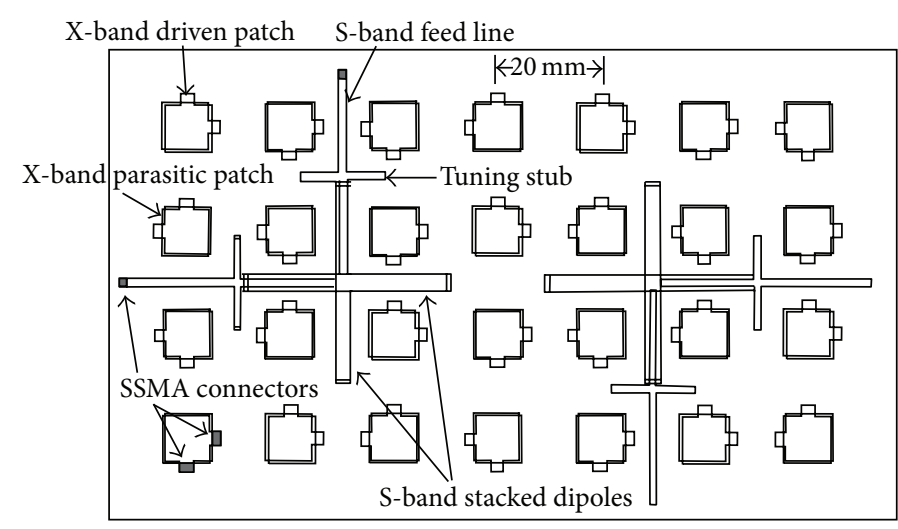

(b)

Figure 28: Dual-band dual-polarized antenna array: (a) side view and (b) top view [65].

linear polarizations or between linear and circular polarization. Polarization agility is an asset to implement on the same hardware platform functionalities with different polarization requirements, such as communication (typically circular) and surveillance (typically linear). Enabling technologies for antenna reconfigurability are switches, variable capacitances, and tunable substrates. These technologies are especially suitable for antennas realized in printed technology. A radiating element in printed technology consists of a metallic surface to which an electric signal is coupled through a guiding line. Switches such as PIN diodes and RF MEMS are typically used to electrically connect/disconnect metallic parts in order to introduce (discretized) changes in the geometry of the total radiating surface. The power handling capability and the lifetime of the switches are important issues. MEMS switches have some advantages over PIN diodes, such as lower insertion loss, lower noise figure, higher quality factor, higher linearity, lower power losses, and very little DC power consumption. However, they show higher actuation voltage and longer switching time. Recent advances in MEMS technology enable the realization of MEMS with improved switching speed and compact size. Varactor diodes provide a capacitance that can be continuously tuned by acting on the diode bias voltage. In view of this, they are typically used as a load to tune the resonance frequency of the antenna element. MEMS with capacitance variable in a given range represent a topic of research but currently available prototypes are not yet sufficiently reliable. Tunable materials, such as ferrite, ferroelectric materials, and liquid crystals are materials whose dielectric properties can be changed by applying an electric or magnetic field. Therefore, they can be used as antenna substrates to uniformly vary the size of the radiating surface therewith obtaining, for example, a change in the resonant frequency or beam steering. At least three approaches can be identified to obtain an antenna able to cover different frequency bands, for example, corresponding to different functionalities: by using very wideband technology, by considering frequency tunable antenna elements, or by implementing dual (multi-) layered arrays. Moreover, if frequency agility is required also filtering of out-of-band signals should be reconfigurable.
Tunable/Switchable Antenna Technology. Among different radiators, an adaptive element will provide the most compact solution and therefore can be easily realized in a dense array. Tunable or switchable narrowband antennas are the best solution when the size and efficiency are important issues. This approach reduces the requirements of the front-end filter compared to a UWB or multiband approach. An adaptive antenna can be realized by changing the physical structure of the radiator, for example, through switches or varactor diodes. However, integrating large number of lumped components (e.g., MEMS, diodes) in the radiating element might increase the power loss, noise, and complexity of the biasing circuitry. For this reason, an alternative approach consists in implementing the switch at the level of the matching network, which is typically located under the ground plane (for antenna in printed circuit board) between the antenna element and the TR module. More recently, antennas which are tuned by varying substrate properties have gained some research interest. Ferrite, ferroelectric material, and liquid crystal are used for these tunable antennas. However, these researches are still at a preliminary state and are facing challenges like reliability, efficiency, accurate control of the material property, and proper modeling.

Wideband Antenna Integration with Tunable Filters. An UWB or multiband antenna makes it possible to cover a very wide bandwidth which can encompass all desired frequencies of operation. Most of the proposed radiating elements are evolutions of the tapered slot antenna and have a threedimensional geometry. Consequently, the main design challenges include feeding network, mutual coupling, and the need of filters for multifunctional operations. An alternative solution is to place the filter in the radiating element itself. This will relax the preselect filter requirements.

Reconfigurable Arrays. This approach involves fully populated individual arrays placed together in a manner as to minimize the interference of one (array) over the other. Elements for both arrays can be combined into individual modules. For the dual layer approach to minimize performance degradation the top array should be nearly transparent to the bottom 
layer. Therefore, the structure of the radiating element should be carefully considered. Moreover, if these arrays have to be made reconfigurable, the corresponding bias lines at different layers would affect the performance of the other layers.

\section{Acknowledgment}

This study is conducted as part of the Sensor Technology Applied in Reconfigurable Systems for Sustainable Security (STARS) project. For further information: http://www.starsproject.nl/.

\section{References}

[1] G. N. Nielson, M. J. Shaw, O. B. Spahn et al., "High-speed, sub-pull-in voltage MEMS switching," SANDIA REPORT SAND2008-0211, 2008.

[2] N. Biyikli, Y. Damgaci, and B. A. Cetiner, "Low-voltage smallsize double-arm MEMS actuator," Electronics Letters, vol. 45, no. 7, pp. 354-356, 2009.

[3] K. Topalli, E. Erdil, O. A. Civi, S. Demir, S. Koc, and T. Akin, "Tunable dual-frequency RF MEMS rectangular slot ring antenna," Sensors and Actuators A, vol. 156, no. 2, pp. 373-380, 2009.

[4] K. R. Boyle and P. G. Steeneken, "A five-band reconfigurable PIFA for mobile phones," IEEE Transactions on Antennas and Propagation, vol. 55, no. 11, pp. 3300-3309, 2007.

[5] W. H. Weedon, W. J. Payne, and G. M. Rebeiz, "MEMSswitched reconfigurable antennas," in Proceedings of the IEEE International Symposium on Antennas and Propagation, pp. 654-657, 2001.

[6] A. Grau and F. De Flaviis, "A distributed antenna tuning unit using a frequency reconfigurable PIXEL-antenna," in Proceedings of the 4th European Conference on Antennas and Propagation (EuCAP '10), pp. 1-5, April 2010.

[7] A. Vasylchenko, X. Rottenberg, B. X. Broze, M. Nuytemans, W. De Raedt, and G. A. E. Vandenbosch, "A frequency switchable antenna based on MEMS technology," in Proceedings of the 4th European Conference on Antennas and Propagation (EuCAP '10), pp. 1-3, April 2010.

[8] J. Balcells, Y. Damgaci, B. A. Cetiner, J. Romeu, and L. Jofre, "Polarization reconfigurable MEMS-CPW antenna for mmwave applications," in Proceedings of the 4th European Conference on Antennas and Propagation (EuCAP '10), April 2010.

[9] A. Grau, J. Romeu, M. J. Lee, S. Blanch, L. Jofre, and F. De Flaviis, "A Dual-Linearly-polarized MEMS-reconfigurable antenna for narrowband MIMO communication systems," IEEE Transactions on Antennas and Propagation, vol. 58, no. 1, pp. 417, 2010.

[10] S. Yang, H. K. Pan, A. E. Fathy, S. El-Ghazaly, and V. K. Nair, "A novel reconfigurable mini-maze antenna for multi-service wireless universal receiver using RF MEMS," in Proceedings of the IEEE MTT-S International Microwave Symposium Digest, pp. 182-185, June 2006.

[11] C.-Y. Chiu, J. Li, S. Song, and R. D. Murch, "Frequencyreconfigurable pixel slot antenna," IEEE Transactions on Antennas and Propagation, vol. 60, no. 10, pp. 4921-4924, 2012.

[12] D. E. Anagnostou, G. Zheng, L. Feldner et al., "Silicon-etched re-configurable self-similar antenna with RF-MEMS switches," in IEEE Antennas and Propagation Society Symposium, vol. 2, pp. 1804-1807, June 2004.
[13] T. Korošec, P. Ritoša, and M. Vidmar, "Varactor-tuned microstrip-patch antenna with frequency and polarisation agility," Electronics Letters, vol. 42, no. 18, pp. 1015-1016, 2006.

[14] S. V. Hum and H. Y. Xiong, "Analysis and design of a differentially-fed frequency agile microstrip patch antenna," IEEE Transactions on Antennas and Propagation, vol. 58, no. 10, pp. 3122-3130, 2010.

[15] C. R. White and G. M. Rebeiz, "Single- and dual-polarized tunable slot-ring antennas," IEEE Transactions on Antennas and Propagation, vol. 57, no. 1, pp. 19-26, 2009.

[16] Y. Tawk, J. Costantine, and C. G. Christodoulou, "A varactorbased reconfigurable filtenna," IEEE Antennas and Wireless Propagation Letters, vol. 11, pp. 716-719, 2012.

[17] P. Ratajczak, J.-M. Baracco, and P. Brachat, "Adjustable high impedance surface for active reflectarray applications," in Proceedings of the 2nd European Conference on Antennas and Propagation (EuCAP '07), pp. 1-6, November 2007.

[18] F. Canneva, J. M. Ribero, and R. Staraj, “Tunable antenna for DVB-H band," in Proceedings of the 4th European Conference on Antennas and Propagation (EuCAP '10), pp. 1-3, April 2010.

[19] M. R. Hamid, P. Gardner, P. S. Hall, and F. Ghanem, "Switchedband Vivaldi antenna," IEEE Transactions on Antennas and Propagation, vol. 59, no. 5, pp. 1472-1480, 2011.

[20] N. Haider, D. P. Tran, A. G. Roederer, and A. G. Yarovoy, "Reconfigurable L/S band phased array," Electronics Letters, vol. 47, no. 23, pp. 1265-1266, 2011.

[21] N. Haider, D. P. Tran, and A. G. Yarovoy, "A new concept for frequency reconfigurable phased-array element," in Proceedings of the Antennas and Propagation Conference (LAPC '11), pp. 1-4, Loughborough, UK, November 2011.

[22] Y. Li, Z. Zhang, W. Chen, and Z. Feng, "Polarization reconfigurable slot antenna with a novel compact CPW-to-slotline transition for WLAN application," IEEE Antennas and Wireless Propagation Letters, vol. 9, pp. 252-255, 2010.

[23] D. Piazza, N. J. Kirsch, A. Forenza, R. W. Heath, and K. R. Dandekar, "Design and evaluation of a reconfigurable antenna array for MIMO systems," IEEE Transactions on Antennas and Propagation, vol. 56, no. 3, pp. 869-881, 2008.

[24] D. Piazza, P. Mookiah, M. D’Amico, and K. R. Dandekar, "Experimental analysis of pattern and polarization reconfigurable circular patch antennas for MIMO systems," IEEE Transactions on Vehicular Technology, vol. 59, no. 5, pp. 23522362, 2010.

[25] J. Ollikainen, O. Kivekäs, and P. Vainikainen, "Low-loss tuning circuits for frequency-tunable small resonant antennas," in Proceedings of the 13th IEEE International Symposium on Personal, Indoor and Mobile Radio Communications (PIMRC '02), vol. 4, pp. 1882-1887, September 2002.

[26] T.-Y. Han and C.-T. Huang, "Reconfigurable monopolar patch antenna," Electronics Letters, vol. 46, no. 3, pp. 199-200, 2010.

[27] D. Peroulis, K. Sarabandi, and L. P. B. Katehi, "Design of reconfigurable slot antennas," IEEE Transactions on Antennas and Propagation, vol. 53, no. 2, pp. 645-654, 2005.

[28] S.-X. Cao, X.-X. Yang, B. Gong, and B.-C. Shao, "A reconfigurable microstrip antenna with agile polarization using diode switches," in IEEE International Symposium on Antennas and Propagation (APSURSI '11), pp. 1566-1569, July 2011.

[29] A. C. K. Mak, C. R. Rowell, and R. D. Murch, "Low cost reconfigurable landstorfer planar antenna array," IEEE Transactions on Antennas and Propagation, vol. 57, no. 10, pp. 3051-3061, 2009. 
[30] Y. Tawk, J. Costantine, K. Avery, and C. G. Christodoulou, "Implementation of a cognitive radio front-end using rotatable controlled reconfigurable antennas," IEEE Transactions on Antennas and Propagation, vol. 59, no. 5, pp. 1773-1778, 2011.

[31] S. J. Mazlouman, A. Mahanfar, C. Menon, and R. G. Vaughan, "Square ring antenna with reconfigurable patch using shape memory alloy actuation," IEEE Transactions on Antennas and Propagation, vol. 60, no. 12, pp. 5627-5634, 2012.

[32] J. T. Bernhard, E. Kiely, and G. Washington, "A smart mechanically actuated two-layer electromagnetically coupled microstrip antenna with variable frequency, bandwidth, and antenna gain," IEEE Transactions on Antennas and Propagation, vol. 49, no. 4, pp. 597-601, 2001.

[33] J. Modelski and Y. Yashchyshyn, "Semiconductor and ferroelectric antennas," in Proceedings of the Asia-Pacific Microwave Conference (APMC '06), pp. 1052-1059, December 2006.

[34] Y. Yashchyshyn, J. Marczewski, K. Derzakowski, J. W. Modelski, and P. B. Grabiec, "Development and investigation of an antenna system with reconfigurable aperture," IEEE Transactions on Antennas and Propagation, vol. 57, no. 1, pp. 2-8, 2009.

[35] A. E. Fathy, A. Rosen, H. S. Owen et al., "Silicon-based reconfigurable antennas-concepts, analysis, implementation, and feasibility," IEEE Transactions on Microwave Theory and Techniques, vol. 51, no. 6, pp. 1650-1661, 2003.

[36] L. Liu and R. J. Langley, "Liquid crystal tunable microstrip patch antenna," Electronics Letters, vol. 44, no. 20, pp. 1179-1180, 2008.

[37] Y. Yashchyshyn and J. Modelski, "Reconfigurable semiconductor antenna," in Proceedings of the 9th International Conference: The Experience of Designing and Application of CAD Systems in Microelectronics (CADSM '07), pp. 146-150, February 2007.

[38] A. Gaebler, A. Moessinger, F. Goelden et al., "Liquid crystalreconfigurable antenna concepts for space applications at microwave and millimeter waves," International Journal of Antennas and Propagation, vol. 2009, Article ID 876989, 7 pages, 2009.

[39] D. Rodrigo, L. Jofre, and B. A. Cetiner, "Circular beam-steering reconfigurable antenna with liquid metal parasitics," IEEE Transactions on Antennas and Propagation, vol. 60, no. 4, pp. 1796-1802.

[40] S. A. Long and G. H. Huff, "A substrate integrated fluidic compensation mechanism for deformable antennas," in Proceedings of the NASA/ESA Conference on Adaptive Hardware and Systems (AHS '09), pp. 247-251, August 2009.

[41] Y. Tawk, J. Costantine, S. Hemmady, G. Balakrishnan, K. Avery, and C. G. Christodoulou, "Demonstration of a cognitive radio front end using an optically pumped reconfigurable antenna system (OPRAS)," IEEE Transactions on Antennas and Propagation, vol. 60, no. 2, pp. 1075-1083, 2012.

[42] R. N. Lavallee and B. A. Lail, "Optically-controlled reconfigurable microstrip patch antenna," in Proceedings of the IEEE International Symposium on Antennas and Propagation, pp. 14, July 2008.

[43] I. Llatser, C. Kremers, D. N. Chigrin et al., "Characterization of graphene-based nano-antennas in the terahertz band," in Proceedings of the 6th European Conference on Antennas and Propagation (EUCAP '12), pp. 194-198, March 2012.

[44] Y. Huang, L. S. Wu, M. Tang, and J. Mao, "Design of a beam reconfigurable $\mathrm{THz}$ antenna with graphene-based switchable high-impedance surface," IEEE Transactions on Nanotechnology, vol. 11, no. 4, pp. 836-842, 2012.
[45] M. Stasiowski and D. Schaubert, "Broadband array antenna," in Proceedings of the Antenna Applications Symposium, pp. 42-59, September 2008.

[46] A. Kumar, "Monopole arrays are electronically steerable," Microwaves \& RF, vol. 45, no. 9, pp. 88-94, 2006.

[47] N. Haider, B. Yang, D. P. Tran, and A. G. Yarovoy, "UWB antenna element for a full-polarimetric antenna array," in Proceedings of the 4th European Conference on Antennas and Propagation (EuCAP '10), pp. 1-5, April 2010.

[48] N. Haider, D. Caratelli, D. P. Tran, and A. G. Yarovoy, "Directive electric-magnetic antenna for UWB applications," Microwaves, Antennas \& Propagation, IET. In press.

[49] N. Haider, D. Caratelli, and A. G. Yarovoy, "Circuital characteristics and radiation properties of an UWB electric-magnetic planar antenna for Ku-band applications," Radio Science, vol. 48, 2013.

[50] S. Nikolaou, N. D. Kingsley, G. E. Ponchak, J. Papapolymerou, and M. M. Tentzeris, "UWB elliptical monopoles with a reconfigurable band notch using MEMS switches actuated without bias lines," IEEE Transactions on Antennas and Propagation, vol. 57, no. 8, pp. 2242-2251, 2009.

[51] D. Manteuffel, M. Arnold, Y. Makris, and Z. N. Chen, "Concepts for future multistandard and ultra wideband mobile terminal antennas using multilayer LTCC technology," in Proceedings of the IEEE International Workshop on Antenna Technology ( $i$ WAT '09), pp. 1-4, March 2009.

[52] G. M. Brzezina, L. Roy, and L. MacEachern, "LTCC ultrawideband antenna with transceiver integration capability," in Proceedings of the European Microwave Conference, vol. 3, pp. 2011-2014, October 2005.

[53] R. Erickson, R. Gunnarsson, T. Martin et al., "Wideband and wide scan phased array micro- strip patch antennas for small platforms," in Proceedings of the 2nd European Conference on Antennas and Propagation (EuCAP '07), pp. 1-6, November 2007.

[54] T. Aboufoul, A. Alomainy, and C. Parini, "Reconfigured and notched tapered slot UWB antenna for cognitive radio applications," International Journal of Antennas and Propagation, vol. 2012, Article ID 160219, 8 pages, 2012.

[55] M. Martínez-Vázquez, O. Litschke, M. Geissler, D. Heberling, A. M. Martínez-González, and D. Sánchez-Hernández, "Integrated planar multiband antennas for personal communication handsets," IEEE Transactions on Antennas and Propagation, vol. 54, no. 2, pp. 384-391, 2006.

[56] G. Srivatsun and S. S. Rani, "Compact multiband planar fractal cantor antenna for wireless applications: an approach," International Journal of Antennas and Propagation, vol. 2012, Article ID 839520, 6 pages, 2012.

[57] J. J. Heikkinen and M. A. Kivikoski, "Directive dual-band CP shorted ring-slot antenna," in Proceedings of the IEEE International Symposium on Antennas and Propagation, pp. 14, July 2008.

[58] D. Caratelli, R. Cicchetti, G. Bit-Babik, and A. Faraone, "A perturbed E-shaped patch antenna for wideband WLAN applications," IEEE Transactions on Antennas and Propagation, vol. 54, no. 6, pp. 1871-1874, 2006.

[59] D. Caratelli, R. Cicchetti, G. Bit-Babik, and A. Faraone, "Circuit model and near-field behavior of a novel patch antenna for WWLAN applications," Microwave and Optical Technology Letters, vol. 49, no. 1, pp. 97-100, 2007. 
[60] G. Cappelletti, D. Caratelli, R. Cicchetti, and M. Simeoni, "A low-profile printed drop-shaped dipole antenna for wideband wireless applications," IEEE Transactions on Antennas and Propagation, vol. 59, no. 10, pp. 3526-3535, 2011.

[61] C. I. Coman, I. E. Lager, and L. P. Ligthart, "The design of shared aperture antennas consisting of differently sized elements," IEEE Transactions on Antennas and Propagation, vol. 54, no. 2, pp. 376-383, 2006.

[62] R. S. Chu, K. M. Lee, and A. T. S. Wang, "Multiband phasedarray antenna with interleaved tapered-elements and waveguide radiators," in Proceedings of the AP-S International Symposium \& URSI Radio Science Meeting, vol. 3, pp. 1616-1619, July 1996.

[63] S. H. Hsu, Y. J. Ren, and K. Chang, "A dual-polarized planararray antenna for S-band and X-band airborne applications," IEEE Antennas and Propagation Magazine, vol. 51, no. 4, pp. 70$78,2009$.

[64] C. Han, C. Rodenbeck, J. Huang, and K. Chang, "A C/Ka dual frequency dual layer circularly polarized reflectarray antenna with microstrip ring elements," IEEE Transactions on Antennas and Propagation, vol. 52, no. 11, pp. 2871-2876, 2004.

[65] X. Qu, S.-S. Zhong, and Y.-M. Zhang, "Dual-band dualpolarised microstrip antenna array for SAR applications," Electronics Letters, vol. 42, no. 24, pp. 1376-1377, 2006. 

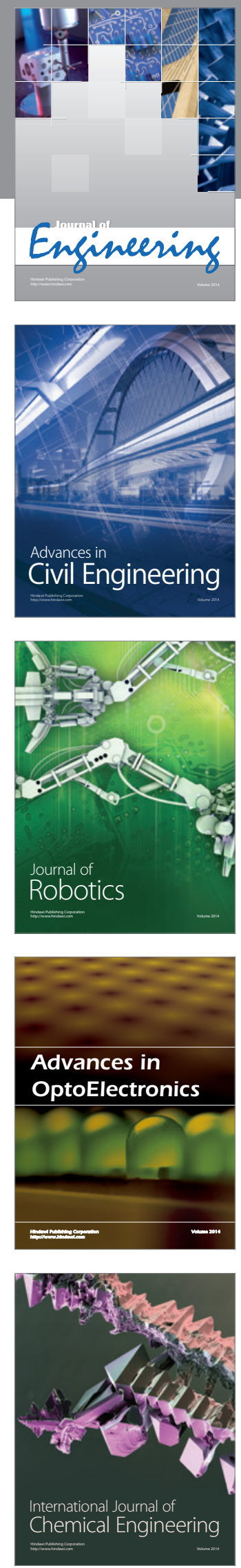

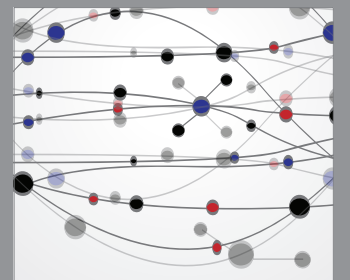

The Scientific World Journal
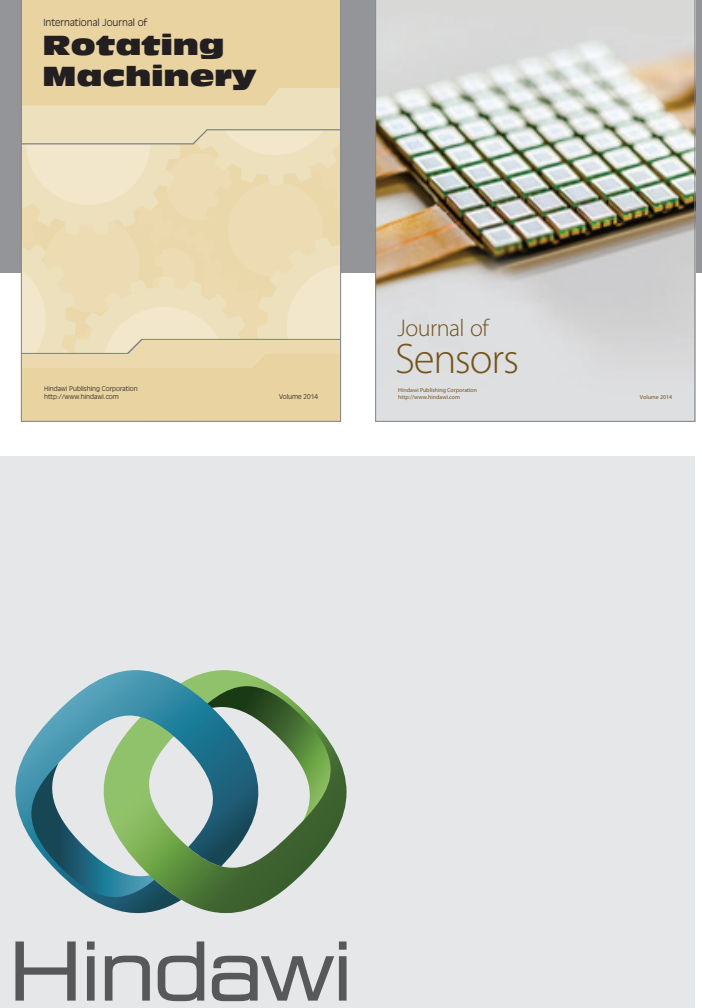

Submit your manuscripts at http://www.hindawi.com
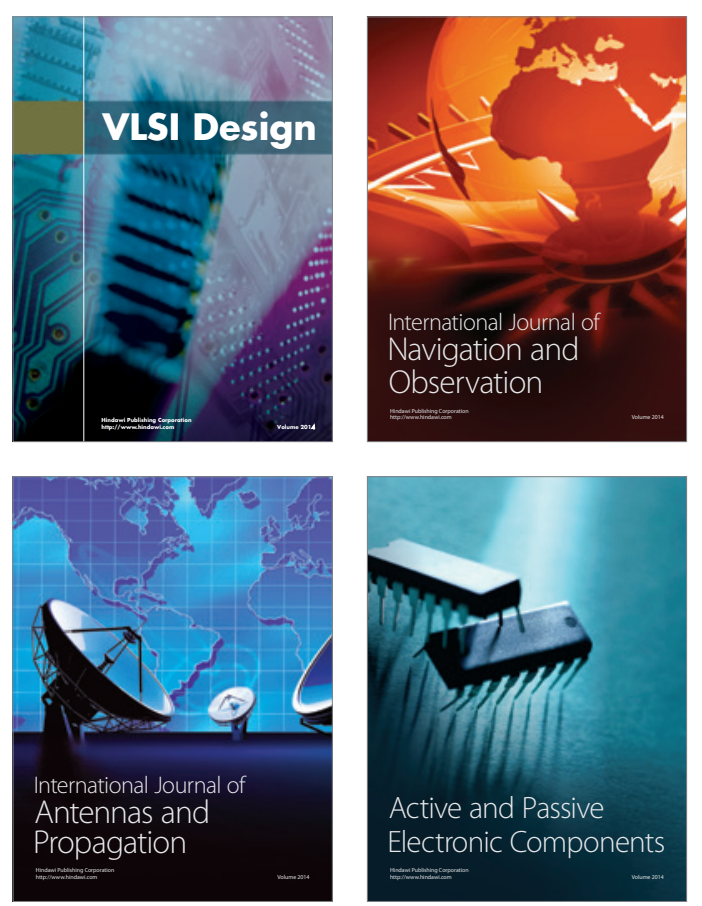
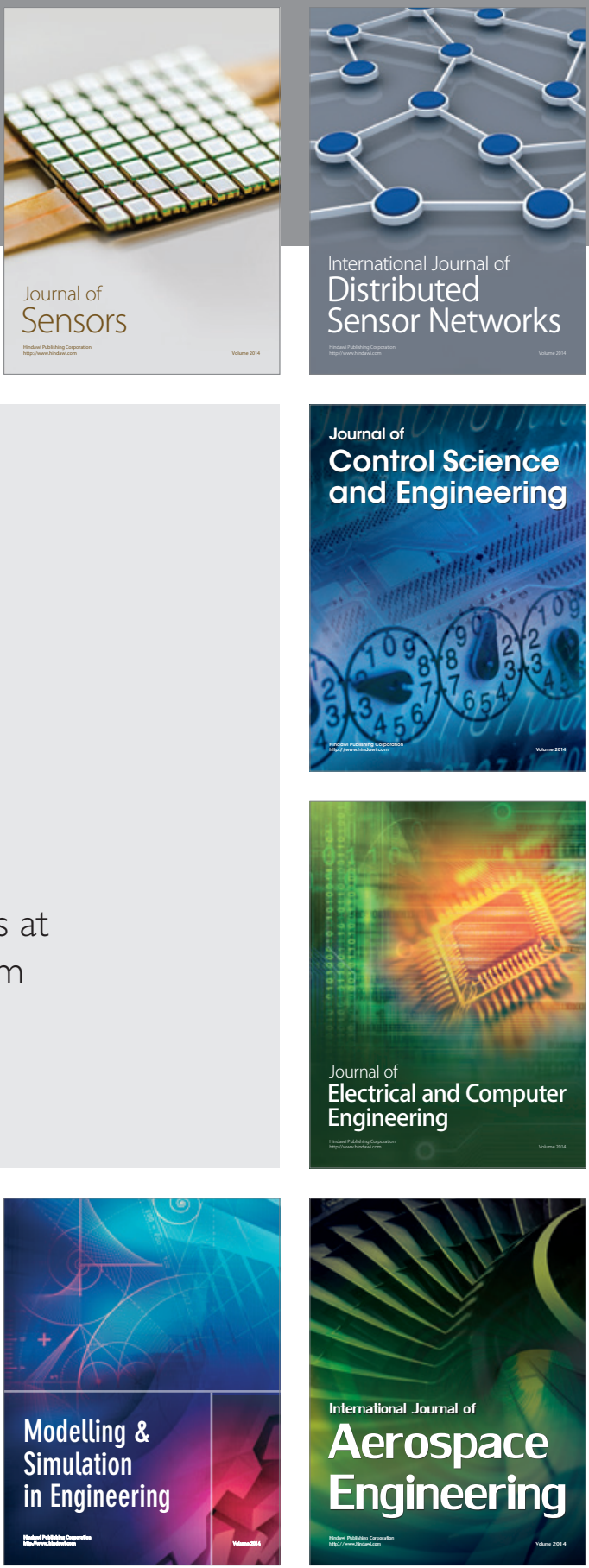

Journal of

Control Science

and Engineering
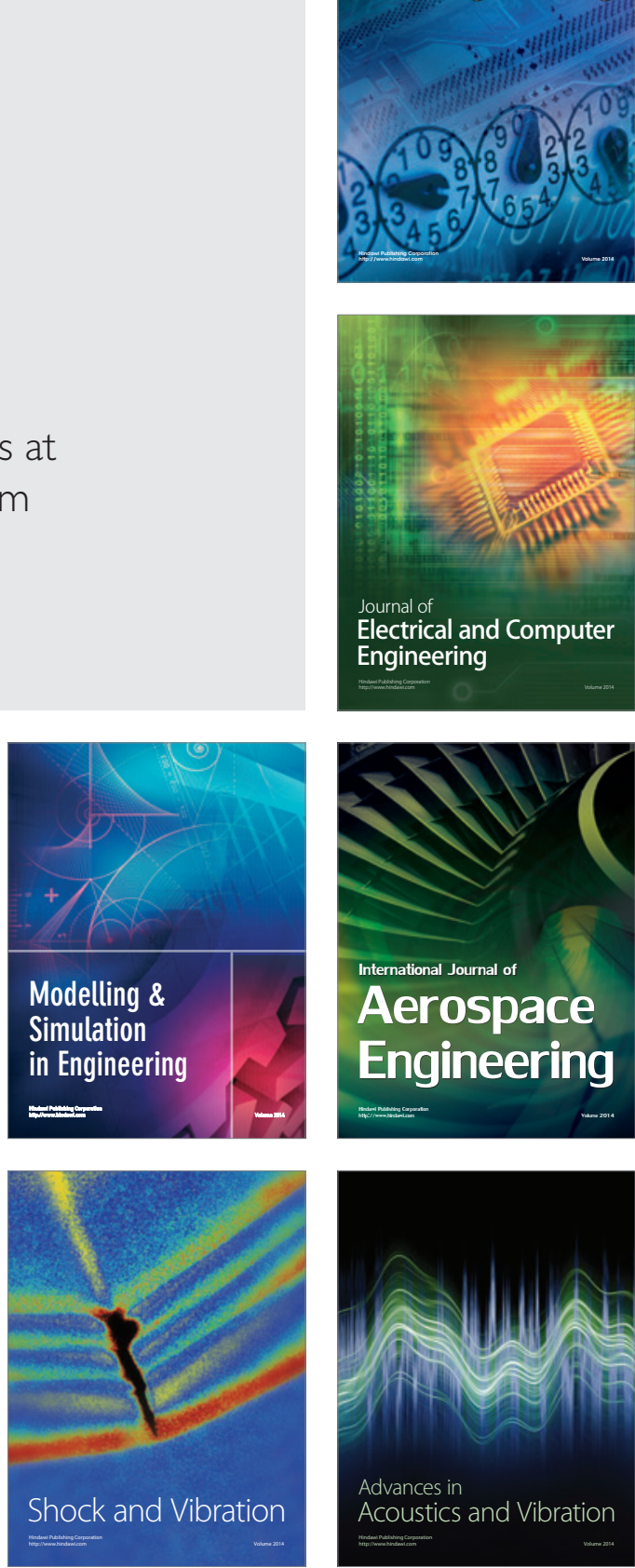